\title{
Ways of Knowing and Power Discourse in Doctoral Examination
}

Terence Lovat

Melissa Monfries

Kellie Morrison

Faculty of Education and Arts, The University of Newcastle, Callaghan 2308, New South Wales, Australia 


\title{
Ways of Knowing and Power Discourse in Doctoral Examination
}

\begin{abstract}
As illustrated in an earlier iteration of this study, the 'Ways of Knowing' thesis of Jurgen Habermas suggests that there is a consistent pattern across discipline areas by which knowledge is revealed and further negotiated, and that this is an important thesis for a project attempting to identify and define patterns of research higher degree examination across discipline areas. Furthermore, this earlier work was able to identify ways in which these patterns revealed themselves in the text of the doctoral thesis examination report, including some case study work on reexamination reports. In summary, this work has concluded that the preponderant mode of assessment employed by examiners resembles closely Habermas's empirical-analytic way of knowing, complete with the potential discouragement of both original thought and genuinely new contributions to knowledge. This article will re-capture the findings of this earlier work and extend the resultant thesis in three ways: first, it will apply to each of the ways of knowing an analysis of the positioning between the examiner and the candidate, summed up in the notions of 'expertise', 'partnership' and 'symmetrical' texts; second it will include an exploration of the ramifications of the thesis for the role played by supervision and supervisors in research higher degree work; and, third, it will begin making connections between the thesis and the literature of power discourse.
\end{abstract}

\section{Introduction: Ways of Knowing}

According to the 'Ways of Knowing thesis of Jurgen Habermas, there is a consistent pattern across disciplines by which knowledge is generated, revealed and further negotiated. For a project attempting to refine our understanding of research higher degree examination across discipline areas, this is an important thesis, Habermas (1972; 1974) identifies three ways of knowing: empirical/analytic (or technical) knowing, historical/hermeneutic (or communicative) knowing, and critical (or self-reflective) knowing. Each of these ways of knowing arises from what he refers to as a 'cognitive interest'. As far as Habermas is concerned, all three interests are operative regardless of the discipline area. Whatever the subject matter, our interest in technical control will lead us to want to know all the facts and figures associated with the subject at hand; this is where the quest for empirical-analytic knowing originates and is of use in the total quest to 'know'. Similarly, our interest in understanding the meaning behind an event will lead us to explore the inner dimensions, to try to relate one factor to another; this impels an historical/hermeneutic type of knowing which serves to extend our understanding and the totality of our knowing. Finally, our interest in ensuring our autonomy as a knower will make us reflect critically on our subject matter, our sources and ultimately ourselves as agents of knowing. This is the preserve of critical or self-reflective knowing and where, according to Habermas, the only truly assured and totally comprehensive knowing occurs.

In earlier work (Lovat et aI., 2002; Holbrook et al., 2004; Lovat, in press), it has been proposed that the Habermasian thesis implies a different relationship between teacher (or examiner) and learner, dependent on the way of knowing that is operative at the time. Where empirical/analytic knowing is operative, the examiner is most likely to be the "expert" in relation to the learner. Where historical/hermeneutic knowing is operative, examiner and learner are more like partners, communicating about meanings and negotiating about understandings. When dealing with knowing of the critical/self-reflective type, the 
relationship between examiner and learner attains a certain symmetry, with the traditional roles potentially reversed. At some point of negotiation and dialogue, the learner may actually be acknowledged as the one in control of the pertinent knowing, and the examiner relegating all power as a result, choosing to accept the role of listener.

Initial analysis of case studies of examination and re-examination reports was oriented by a focus on examiner/candidate text. This analysis suggested that the preponderant mode of assessment employed by examiners resembled closely the parameters of the empirical/analytic way of knowing, with largely negative text that spoke loudly of examiner as 'expert', and little to no evidence of text that revealed symmetry or the awe of the listener as new knowledge boundaries were being shaken. This lack of synthesis obtained even with theses that had been given 'top box' or unqualified pass, and so presumably representing the architecture of original contribution. The case was made that we may well be dealing with a virtual genre in the examination text, to some extent regardless of the quality of work under examination. The case was further made that, were such a dominant genre in the examination script to be revelatory of the entire regime of the $\mathrm{PhD}$, the potential was there for routine discouragement and even obstruction of the 'original contribution' that is meant to be the over-riding assessment item of the $\mathrm{PhD}$. Indeed, it was supposed that a $\mathrm{PhD}$ regime replete with boundary shaking and original contributions would be evidenced by an examination genre that was fairly well filled with positive comment, at the least, and perhaps even robust self-reflective script.

The present article extends on the earlier analysis to include an exploration of the role of the supervisor, from the perspective of the examiner, as gleaned from the textual form of the doctoral examination report. Again, more evidence was found for the assertion that the dominant way of knowing, and the relationships constructed in the reports, emphasized a technical rather than reflective regime, albeit there was more indication of the latter than in the earlier study.

\section{Theoretical Base: The Unity of Knowledge}

Habermas's perspective on the unity of knowledge is part of the heritage of modern work dating at least to Dewey $(1922 ; 1956 ; 1956 a)$ and the attempt to identify the standard patterns that underpin knowing, learning and instruction. Tyler (1949) generated from this conceptual identification a virtual science around assessment regimes, work that was built on in the taxonomies of educational objectives of Bloom (1956) and Krathwohl et al. (1964).

Habermas's (1972; 1974) explanation for apparent divisions in knowledge reality derives from his belief that knowing is impelled by a series of 'cognitive interests', interests which are part and parcel of the way the human mind works. These interests are three-fold. First, there is an interest in technical control which impels an 'empirical analytic' type of knowing. Second, the interest in understanding meanings gives rise to an 'historical hermeneutic' way of knowing. Third, there is an interest in being emancipated, a free agent as it were, which issues in a 'critical', or 'self-reflective' form of knowing.

A vast amount of important educational research has been spent in making application of the Habermasian thesis to a range of issues relevant to educational theory and practice (Van Manen, 1977; Young, 1989; Doll, 1993), and Habermas (2001) acknowledges the validity of this connection in some of his later work. This validation is essential for the authenticity of connecting Habermasian theory to the world of higher degree supervision and examination where, it is being contended, a unity of knowledge theory allows us to trace and track patterns of thought, expectation and text across a range of discipline areas.

At the heart of Habermas's thesis is the notion that the cognitive interest to be emancipated, or free, in our knowing impels an intensive critique of all of the assumptions 
and sources of our knowing up to that point in time. Among the assumptions and sources are those of both the external and internal world. Externally, one confronts one's enculturated past, one's corporate beliefs and community values, one's family, school, political and religious heritage. Internally, one confronts one's self: there is no knowing without knowing the knower. Through critical, self-reflective knowing, one is challenged to let go of much of the past and to embrace new futures. The end of critical, self-reflective knowing is praxis, practical action for change. One cannot remain in the same place once one has confronted one's past and one's self. The proposition of earlier work in this series is that this is the form of knowing one might expect to be dominant in a learning regime that is purportedly about the change we title 'original contribution'.

\section{Self-reflective Knowing and Teacher/Learner Positioning}

As suggested above, when dealing with knowing of the critical/self-reflective type, the traditional roles of teacher/supervisor/examiner and learner attain a certain symmetry, with much relegation of power by the former as the learner is endowed with the confidence and the power of being in control of their own knowing. This can even result in the former, in a sense, sitting at the feet of the learner in the role of listener. If the listener wishes to know what the learner has learned, and even more so if the listener wants to 'know' what the learner now knows, then she/he will be dependent upon the learner sharing what is known. The challenge here for any traditional modes of teaching/learning relates to the fairly obvious truth that learners may often 'know' in ways that are beyond the knowing of the teacher. It is no different when it comes to the phenomenon of examination. In the empirical/analytic domain, it would be intolerable that the learner might be said to know more than the examiner. In the historical/hermeneutic regime, this is tolerable and able to be negotiated. In dealing with critical/self-reflective knowing, it is to be expected and indeed celebrated that new knowing, quite beyond the first hand knowledge of the examiner, has occurred. Granted the 'original contribution' thesis of what is held to be the zenith of our learning instruments, one might expect to find this occurring more frequently in the $\mathrm{PhD}$ process, and especially in its ultimate point, the examination, than anywhere else. Van Manen (1977) may well capture the relationship between teacher/supervisor/examiner and the learner that is being suggested here when he says the following of the type of learning he sees ensuing from critical/self-reflective knowing:

The norm is a distortion-free model of a communication situation ... (where) there exists no repressive dominance, no asymmetry or inequality among the participants of the educational process. (p. 227)

For Van Manen, like Habermas, it is at this point alone that education, and presumably examination, becomes distinctively ethical, characterized by a sense of justice, equality and the freedom of individuals to follow their instincts of knowing wherever they might lead. It is also the way of knowing which, it is said, is a necessary precursor to the stretching of the boundaries of knowledge, to genuinely new knowing taking place. If one were to take Van Manen's 'no asymmetry' thesis seriously, one would surmise that the only form of examination that could do justice to, or perhaps even detect, originality of this type would be one which was conducted largely in self-reflective mode. As suggested, earlier work in this series concluded that such a mode was rare, if one can take seriously the genre of the text (Lovat, 2004).

Even when dealing with 'top box' theses, the preponderance of negative text was striking. One case study of such a thesis illustrated three highly castigatory examination reports, with comments including: "shortcomings in the way the thesis is argued," "... analysis which is very limited in scope,” “... does not deal with the arguments,” “... without an acknowledgment of its underlying arguments,” “... understandings are so limited,” “... reading ... is very limited," "Most important are weaknesses in the structure of the thesis.” In 
spite of such derisory assessment, all three examiners, by recommending a 'top box' pass, presumably rated the thesis as constituting a major contribution to the world of public knowledge. This serves to illustrate the point that, in the PhD examination report, we may more often than not be dealing with a particular type of text, a virtual literary genre, born of assumptions about the nature of the task and its incumbent duties, as well as about the relationship between the examiner and the student.

In the earlier study, there was only one report that offered a text providing some clear indication of a different mode of thought and positioning. It began with the words:

There are those pleasant occasions when one is asked to review a paper or examine a thesis and you wish that you had written it I believe that this is one of those experiences.

Such a beginning clearly positions the examiner's relationship with the student away from one of expertise and even negotiability. The relationship established is at least symmetrical and could even be argued to be one of awe on the part of the examiner towards the student's original contribution, one which the examiner admits she/he had not themselves made. In that sense, the student has exceeded the expertise of the examiner and, in a rare display, this examiner is prepared to admit it.

In this case, the examiner goes on to specify in precisely which ways the student's work had exceeded his/her own, including adding value to the examiner's own work. That is, in a sense, the student has helped the examiner to understand the latter's own work:

I thought that the interpretation of my work was very interesting as I had quite a lot of trouble digesting the data and simplifying it to explain what was happening and why $X$ interpretation of this and his approach ... demonstrate how a fresh approach by a creative researcher... can re-interpret source data to add value and create or develop valuable new knowledge. When I think of my work now in these... terms, I find that the results become more meaningful.

In the last sentence, the examiner makes explicit the self-reflectivity impelled by reading the thesis, including being brought to an enhanced understanding of her/his own work.

The purpose of the work captured in the current article was to see if the application of the Habermasian schema to those sections of the text where the focus was on the examiner's relationship with the thesis supervisor (rather than the candidate) produced similar or different results.

\section{The Expertise Text: Supervisors as Gatekeepers}

The majority of the examiners' comments that explicitly referred to the supervisor were focussed on custodial work, or gate-keeping. In contrast to the paradigm of reflective knowing articulated by Van Manen (1977), inequality and asymmetry between the participants in the educational process of the examination were evident. The hierarchical implications were two-fold, as examiners positioned themselves over supervisors, and both examiner and supervisor were positioned over the candidate. The examiner, positioned as expert and custodian of a body of technical and conventional knowing, often outlined to both supervisors and the learners, the ways in which the thesis must conform to particular standards and reproduce particular bodies of knowledge (eg. sufficiently broad literature review, appropriate methodology and accurate application of it, etc.). The following excerpt represents the many texts that typically highlighted how examiners reinforced the role of supervisor as gatekeeper:

...the changes specified in my report and marked in the thesis need to be addressed to the satisfaction of the supervisor.

At times, this 'delegation' by the examiner saw the supervisor and candidate as jointly 
responsible for the further development and repair of the thesis:

I would encourage the candidate and her supervisors to make the necessary modifications to this thesis.

Here, the responsibility for polishing the thesis to the appropriate level rests with both the candidate and the supervisor.

At other times, the examiner's authority over the supervisor is unmistakably demarcated through a strong reprimand about the quality of the thesis. Here, we see obvious surveillance by the 'expert', not only of the candidate, but also of the supervisor. The gaze of the examiner, it seems, in doctoral examination is not restricted to the learner. That is, candidates are often not singularly criticized; rather, criticism is also applied to the standards of supervision as well.

In terms of direct instructions to supervisors or negative comments about their supervision, much of the examiner's language articulates a clear expectation that a primary role of the supervisor is to ensure that the thesis under examination is of an appropriately high technical standard. When this does not occur, the hierarchy between examiners and supervisors is evident in examiners' directions. For example, one examiner commented that “... a final and careful proofreading from the supervisors is required." While another commented on more serious statistical oversights that needed to be addressed during future supervision:

I strongly urge these advisors to get their students to use standard deviations and to show confidence limits henceforth. They should at least insist on exact p values, so that others can work out the confidence limits.

Another examiner urged in the following way:

Both the candidate and supervisors (should) remedy these aspects before final acceptance.

Such comments would seem to indicate that the process of doctoral examination can be as much an examination of the supervisor's expertise as of the ability of the student and quality of the thesis. Supervisors are therefore reproached, sometimes quite severely, when they have not been sufficiently meticulous in their duty to guide the thesis to conform to appropriate standards, have provided insufficient guidance, or have failed to perform adequately in some other way, as indicated in the comments below. These comments also highlight that candidates do not have to bear criticism of their work alone:

I note that the candidate has not had the benefit of direct supervision by an expert in the field and therefore believe that responsibility for the ultimate product does not solely lie with the candidate.

All of the above matters should have been dealt with during the draft stages of the thesis and reflect badly on the supervisor more so than the candidate.

These [a previously stated list of errors] all suggest a rather lax critical review of the thesis by the supervisor(s) and should be corrected in the Library copy.

Some of the harshest criticism of the supervisor was evident in the lengthy comment reported below. Here, the examiner had been very impressed with some aspects of the thesis, but obviously felt that the candidate's supervision was substantially deficient, and over the course of the examination report, remarked at length on the poor quality of supervision:

It seems only just I should state at the outset that it was quite obvious that $X$ had not received a level of supervision that would enable him/her a more critical discursive approach to what is a quite remarkable and idiosyncratic project.

...I describe earlier a concern regarding supervision; it seems remarkable that such a 
vivid imagination as is described here and such a capacity for the construction of narrative was not given guidance to reach the potential of this research ... relates to the supervisor's role, for work of this quality to be so undernourished, unsupervised is tragic.

Occasionally, such reprimands are extended beyond the supervisor to the responsibility of the whole institution. For example, the two comments below originate from different examiners and refer to different institutions:

I strongly recommend that the University of more closely scrutinize PhD theses sent for external examination to ensure that they, at least, contain minimal spelling and simple English grammatical errors.

In summary, it seems that the same preponderantly 'expertise' text, identified in the earlier work regarding the positioning of the examiner in relation to the candidate (Lovat, 2004) extends fairly widely to position the examiner as 'expert' in relation to the supervisor as well. Furthermore, this same text implicitly positions the supervisor in an expert role against the candidate. Indeed, examiner expertise text tended more often than not to blur any distinction between comments made about inadequate supervision and the implicit assumption that the main role of the supervisor was as gatekeeper. Within this text, there tended to be no allowance given for other conceptions of supervisor role. Nor was there much evidence of the extension of that mercy that was occasionally offered to the candidate being also offered to the supervisor. In other words, blaming the supervisor (or host institution) was occasionally seen to let the candidate 'off the hook'. For poor supervision, however, there were no excuses.

\section{Partnership Text: Supervisors as Co-constructors}

In this section, the effort was to establish instances of what were broadly titled 'partnership texts', in order to ascertain whether a fundamentally different positioning was occurring between the examiner and the supervisor and, if so, whether this was resulting in a different conception of knowing being addressed. The knowing being searched for here was one conforming to Habermas's 'communicative' (or historical/hermeneutic) knowing, where positioning would approximate negotiation between peers, rather than the clearly unequal relationship to be found in expertise text. Granted the assertion above that the positioning of examiner against supervisor tended to blur with assumptions by the examiner about the proper role to be played by the supervisor in relation to the candidate, a logical place to begin this exploration seemed to be with the comments of the examiner about this latter relationship. It was from this exploration that the notion of 'partnership text' arose. When something had gone wrong with the thesis, in the view of the examiner, there was a disinclination to blame both parties at once; this seemed to be evident in the expertise texts surveyed above. Either the student or the supervisor was held to account. However, where praise was to be given, invariably it was offered to the candidate and the supervisor, as though they were a team. The praise from different examiners reported below represents typical partnership text:

...I believe that the student and supervisor should be congratulated for bringing together an excellent examination of this very sensitive area.

I would like to congratulate the student and advisor on a well-done thesis. Both he and his supervisors need to be congratulated. It is very heartening to see such high quality.

It is clear that the candidate had access to outstanding supervision and methodological support. I would like to extend my congratulations to the supervisory committee. 
It reflects well on both the candidate and the supervisor.

This was a great piece of work and both the candidate and supervisors are to be congratulated.

I extend my congratulations to $X$ and his committee for an outstanding piece of research.

\section{Please convey my congratulations to $X$ and Prof $Y$ for this excellent work.}

In these comments, we repeatedly see examiners articulating a role for the supervisor quite beyond being a gatekeeper; it is rather a role as partner with the student, and even as coconstructor of the thesis. One examiner even went so far as to imply that the research within the thesis was the supervisor's own, to publish at will:

I found the research to be of a high standard and there is no doubt a considerable amount of it will be published by the supervisor in internationally recognized ... journals.

Such an assumption, if proven to be correct, could actually have serious implications for the idea that a doctoral thesis has to be the candidate's original work and that it is the candidate who is contributing to the development of new knowledge. To what extent is a thesis the candidate's own, when an examiner seems to regard the partnership as indispensable to the success of the thesis? This may amount to an overestimation of supervisor as partner, however that is for another study.

So, to the central issue of whether partnership text portrays a different positioning between examiner and supervisor, or supervisor and student, and whether there might be a different way of knowing coming into focus. On the one hand, there would seem to be a different assumption evident about the relationship between the supervisor and the candidate, with a greater sense of peer interaction being evident. On the other hand, there is little in the partnership text that fundamentally changes the positioning of the examiner against the supervisor, or indeed the candidate. While the text is more positive, and in some cases quite full of praise, the position of the examiner is still essentially one of expert opinion, making judgments from on high. There is little in the text that speaks of symmetry in the relationship with either the candidate or even the supervisor, and so it seems the empirical/analytic way of knowing endures throughout the text as the dominant form, albeit slightly modified by an element of the communicative.

\section{Symmetrical Text: Learning from Supervisors and their Candidates}

According to the 'no asymmetry' thesis of Van Manen, it is possible for roles to be reversed, with the examiner relegating to the supervisor (and sometimes the candidate) the power that is clearly bestowed by the examiner role. A rare example was provided above of the type of text that portrays this relegation. In this part of the study, a larger number of such texts have come to light. Granted that this part of the study has concentrated on text pertinent to the supervisor, it may indicate that there is a stronger disposition by the examiner towards relegation to the supervisor than to the candidate. The comments below provide some glimmer of the different positioning that occurs when a measure of self-reflective knowing becomes instrumental:

The student and the advisor clearly know more about these techniques than I do.

I recommend the thesis for the award, and I leave it up to the candidate and his advisor to decide whether, and to what extent, suggestions listed below should be incorporated into the thesis.

In these examples, the examiners reduce the focus on themselves as expert, a view which 
underpins technical knowing, and opens the door for a relationship of learning that is more equitable and fluid. The first comment is a complete and apparently comfortable relegation of expertise about method. This examiner is prepared to sit at the feet of both the candidate and the supervisor regarding technique. The second examiner more subtly relegates the final decision on the best course of action to both the candidate and the supervisor, making it clear in the words, "I leave it up to the candidate and his advisor ..." that they might know better than the examiner what the final requirements should be. The notion that any recommendations are negotiable not only opens the door for interpretive dialogue to occur but, moreover, acknowledges that the supervisor and candidate possess knowledge that the examiner does not currently hold. The entire examination process is changed by such an approach, exuding negotiability, admission of the possibility of supervisor and candidate superior knowledge, and generally the use of a language that positions a different type of relationship between the three parties. The text qualifies for the term 'symmetrical' and it clearly relegates to the supervisor and the candidate much of the power over the process.

Other examples of symmetrical text include:

I benefitted from reading it, and I congratulate the author and her advisers on their work.

Each time that I have been asked by Australian academic supervisors to referee $\mathrm{PhD}$ theses, I have found myself amply rewarded and stimulated. $X$ 's thesis is not an exception to this rule. The high quality of your thesis speaks eloquently about Australian pedagogy and apprenticeship.

Of note in the above texts is the admission by the examiner of having benefitted and actually having learned from reading the thesis. This is the kind of text that accords with a process designed to elicit an original contribution to knowing. The examiners are reversing the roles and sitting at the feet of both candidate and supervisor. This positioning and the acknowledgment of originality is made even more explicit in the comments below:

My congratulations to her and her supervisor for the achievement of a valuable, original contribution to knowledge.

I applaud $\mathrm{Mr} X$ and his supervisors, $\mathrm{Dr} \mathrm{K}$ and $\mathrm{Dr} \mathrm{Z}$, for a very comprehensive, high quality innovative, and forward thinking research report. The thesis clearly breaks new ground on ...

This thesis reports on research work on the further development of a new and unique method, originally developed and reported by ' $\mathrm{K}$ ', a supervisor for this thesis ... Congratulations to the candidate and to his supervisors for an outstanding piece of research and reporting.

While these latter texts do not contain explicit admission on the part of the examiner of having benefitted and/ or learned from the thesis, one could deduce that such strong endorsement of original work would imply such admission. Presumably, one cannot both endorse new knowing having occurred while, at the same time, claiming to have known it all along. These latter texts are among the strongest of symmetrical texts yet uncovered for they both identify sharply that original contribution has occurred and, at the same time, portray relegation of power by the examiner to the learner and to the supervisor.

In summary, the further the study moved into a consideration of supervisor text, the more one could begin to detect some relegation of the power defined by expertise text, a relegation altogether rare when examiners address candidates directly. However, even in consideration of supervisor text, the dominance of empirical/analytic driven expertise was marked. The 
thesis derived from the earlier study that the doctoral examination report constitutes a virtual genre has been modified by this later study, but in no way subverted. It was as a result of this new-found certainty that the author team turned to the literature and perspectives of power discourse and their application to the case study data.

\section{Expertise and the Discourse of Power}

The fact that the dominant way of knowing discerned in the examination report was that of 'expert', and this even in the scripts of those ultimately judged to be unqualified passes, leads to a consideration that examiners may, as a matter of course, engage in some form of power discourse as part of the cultural artifact of the doctoral examination. Corson (1995) sees language as the prime instrument of power, in terms of both its construction and deconstruction. It is consistent with his thinking, therefore, that the doctoral examination report should provide an effective means of assessing power relations between the examiner and the candidate.

Furthermore, the definition of power provided by Dacher, Gruenfeld and Anderson (2003) provides a strong theoretical base for discourse analysis. They define power as the capacity to modify an individual's state by providing or withholding resources, a definition which clearly encompasses the role of the examiner in the doctoral examination process. This definition also seems to find a point of consistency with the epistemic views of Habermas who, among other things, provides a rubric for partnerships where resources (namely knowledge and expertise) are negotiated around different bases of power.

Given the findings above regarding the doctoral examination reports under study, the proclivity to temper evaluations of even the most outstanding theses with negative comments could be interpreted as the examiner embracing the power base which is offered by the process, be this a conscious or unconscious intention. Such thoughts are consistent with research attesting to the influence of power in evaluative contexts. Georgesen and Harris (1998), for instance, found that as power levels increased within organizational contexts, evaluation by those in authority tended to become increasingly negative while selfevaluations by those enjoying the power of the structure tended the other way. This suggests that those in power often accrue power by rhetoric that, at one and the same time, elevates their own position by offering negative evaluation of their subordinates.

Doctoral examination should, by its very nature, yield concrete measures of academic achievement against specified criteria for successful completion. However, the fact that the examination text appeared to be consistent regardless of the final estimation of the thesis's worth, has led to the proposition that some of the ways of wielding power noted in the literature on power discourse in organizational life generally (cf. Cole, 2004) is also operative in the organization known as 'doctoral examination'. The best way of testing this seemed to be to concentrate on the text to be found in those theses finally rated as 'accept as is' or, more colloquially, as 'top box'. This led to more intense analysis of a number $(n=23)$ of such thesis reports.

Of immediate interest was that, in these 'top box' reports, not one examiner referred to the candidate as a 'researcher'. When not using their names, students were referred to as 'author', 'candidate', 'applicant and, in one instance only, as 'investigator. This may have provided an early clue that the disparity in expertise was being preserved through a labelling that ensured the candidate could not begin to assume the role of researcher, which might imply some 
measure of equal status with the examiner. If this is the case, a conscious or subconscious use of labelling in the text serves to reinforce the power imbalance between supervisor and candidate and, according to the social cognitive literature, would serve to enhance the supervisor's self-image of the self (Georgesen and Harris, 1998) and predispose him/her to engage in negative evaluations, thus ensuring the candidate is 'kept in their place'.

Contrary to Van Manen's paradigm of self-reflective knowing leading to 'non-asymmetry', where the examiner might be transformed by the new knowledge offered in the doctoral thesis, there was in fact overwhelming evidence of the rhetoric of 'gate keeping', seen in comments such as :

This is a strong claim for which little evidence exists so far.

... a nil effect is found because an experiment lacks power.

... in some respects the thesis is almost too original.

Such comments suggest that there is a standard to which candidates must conform and, regarding the last quote that even when originality begins to infect the candidate, the latter is under some obligation to temper it with a sense of the protocol that surrounds the doctoral examination process, including preserving the examiner's and candidate's proper place in the scheme of things.

The intense study of 'top box' theses did render some text that represented the kind of selfreflective knowing Habermas would expect to find in the doctoral examination report. This 'meeting of minds' or 'non-asymmetry' could be seen in the following:

... this is such a well-written and absolutely convincing thesis that I am at a loss for words.

I found this thesis most enjoyable reading and am sure that many of these fundamental observations will become primary references to the field of ...

Such comments were, however, extremely rare among the reports of what were purportedly the most superlative theses under study. Again, one is forced to ponder on Corson's (1995) notion that power is an all encompassing attachment at all levels of education. His assessment is that educational settings and the formal processes that legitimize them provide one of the more natural contexts for power to be wielded. There is, after all, an inherent asymmetry connoted by the very notion of 'being educated'. Whether the power inherent in education is turned ultimately to the good of individuals and to the overwhelming goal of generating new knowledge for a new generation, or whether it is utilized primarily to preserve the selfinterests of those doing the 'educating' and their institutions, is one of the issues that Corson strives to uncover. The other issue is the more direct one about the extent to which formal educational processes empower or disempower those who subject themselves to them.

The majority of examiners represented in this intense phase of the study did acknowledge at some point in the examination report that the thesis was of sufficient standard to receive an unqualified pass. As indicated above, a small number of examiners even allowed for some of the symmetry of relationship that would characterize self-reflectiveness on their part. For the most part, however, the examiners were relentless in their criticisms of these apparently excellent theses, including about fundamental issues related to the very way the study might have been conducted. In this, the evidence here replicated that identified above where a 'top 
box' thesis was castigated by all three examiners for its content, method and procedures. Clearly, it seems, this is not a rare occurrence but it does remain a particularly mystifying one.

\section{Conclusion}

The findings so far would seem to substantiate further the earlier thesis (Lovat et al., 2002; Lovat, 2004) that the empirical-analytic way of knowing is the relatively dominant mode employed in the examination report. This paper extends on earlier analysis to show a dominance of empirical/analytic text in the examiners' reference to the role of the supervisor. Just as such text is likely to discourage too much innovation on the part of candidates, as earlier research has suggested, so it is likely to encourage supervisors to focus in their own work with the candidate on the technical, rather than historical/hermeneutic or critical/selfreflective knowing potential of a thesis. In other words, knowing that such text is likely to dominate the examination process may well encourage supervisors to play safe in the mentoring of the thesis, rather than risk too much of the kind of boldness normally found as an attachment to the truly new and contributive.

The second way of knowing, historical-hermeneutic, was also identified in the textual meanderings of the examiners, but to a less significant extent. It was wrapped in more positive and encouraging language, and invited a modicum of partnership. In the end, however, it was judged not to have moved the essential expertise positioning found essentially when dealing with the empirical/analytic. The findings did extend on the instances collected so far of text resembling a focus on self-reflective knowing and so moving the positioning between examiner, supervisor and candidate more towards one of symmetry and occasional awe at the emergence of new knowing. As illustrated above, the greater number of such texts found when the supervisor was drawn into the examiner/candidate relationship may reveal an enhanced disposition on the part of examiners to relegate some power over the process to the supervisor, while still being guarded about doing so to the candidate.

Finally, the research to this point in time has spoken increasingly of power relations, a theme that may require further follow-up, granted the delineation of relationships of power evident in the positioning between examiners, supervisors and candidates. Just how is the power that is implicit within any educational process being played out in the doctorate and to what extent may the examination process be symptomatic of this playing out, are issues that this study hopes to address in greater detail as it unfolds.

In conclusion, it is sobering that, to date, there is so little evidence of the kind of examination regime that would clearly separate the doctoral process, purported to constitute the zenith of learning, from more junior educational processes where a gate-keeping regime may well be appropriate. As suggested above, this fact has to raise questions about the extent to which the doctorate is truly working for individuals and society as the agency of new knowledge and creativity that is supposed to be its signature. 


\section{References}

Bloom, B. (ed.) (1956). Taxonomy of educational objectives: Book 1 cognitive domain. London: Longman.

Cole, P.T. (2004). Implicit theories of organizational power and priming effects on managerial power-sharing decisions: An experimental study. Journal of Applied Social Psychology, 34, 297-321.

Corson, D. (1995). Discourse and power in educational organizations. Cresskill, NJ: Hampton.

Dacher , K., Gruenfeld, D.H. \& Anderson, C. (2003). Power, approach and inhibition. Psychological Review, 110, 265-284.

Dewey, J. (1922). Human nature and conduct: An introduction to social psychology. New York: Modern Library.

Dewey, J. (1956). The child and the curriculum. Chicago: University of Chicago Press.

Dewey, J. (1956a). The school and society. Chicago: University of Chicago Press.

Doll, W. (1993). A post-modern perspective on curriculum. New York: Teachers College Press.

Georgesen,J.C. \& Harris, M.J. (1998). Why is my boss always putting me down? A metaanalysis of power effects on performance evaluations. Personality and Social Psychology Review,3, 184-195.

Habermas, J. (1972). Knowledge and human interests. (transl. J. Shapiro) London: Heinemann.

Habermas, J. (1974). Theory and practice. (transl. J. Viertal) London: Heinemann.

Habermas, J. (2001). The liberating power of symbols: Philosophical essays. Cambridge: Polity Press.

Holbrook, A., Bourke, S., Lovat, T. \& Dally, K. (2004). PhD theses at the margin: Examiner comment on re-examined theses. Melbourne Studies in Education, 45, 89-115.

Krathwohl, D., Bloom, B. \& Masia, B. (1964). Taxonomy of educational objectives. Handbook II affective domain. New York: McKay. 
Lovat, T. (in press). 'Ways of knowing' in doctoral examination: How examiners position themselves in relation to the doctoral candidate. Australian Journal of Educational and Developmental Psychology.

Lovat, T., Holbrook, A., Bourke, S., Daily, K. \& Hazel, G. (2002). Examiner Comment on Theses that have been Revised and Re-submitted at Annual Conference of the Australian Association for Research in Education (AARE), The University of Queensland, Brisbane.

Lovat, T. \& Smith, D. (2003). Curriculum: Action on reflection. (fourth edition) Sydney: Social Science Press.

Stenhouse, L. (1975). An introduction to curriculum research and development. London: Heinemann.

Tyler, R. (1949). Basic principles of curriculum and instruction. Chicago: University of Chicago Press.

Van Manen, M. (1977). Linking ways of knowing with ways of being practical. Curriculum Inquiry, 6, 205-228.

Young, R. (1989). A critical theory of education: Habermas and our children's future. New York: Harvester Wheatsheaf. 